\title{
Analysis of Innovative Projects Portfolio on the Basis of the Resource Saving Criterion
}

\author{
Sergey Malikov \\ Open Joint-Stock Company Scientific and Research Institute of Super COMPUTER \\ Moscow Witte University \\ Moscow, Russia \\ E-mail: sergej.malikov@bk.ru
}

\author{
Alla Nikonorova \\ Moscow Witte University \\ Moscow, Russia \\ E-mail: nikonorova-av@mail.ru
}

\author{
Dmitry Morkovkin \\ Financial University under the Government of the Russian \\ Federation \\ Russian University of transport (MIIT) \\ Moscow, Russia \\ E-mail: MorkovkinDE@mail.ru
}

\begin{abstract}
The article considers the algorithm for comparing of implementation of innovative projects plans on the basis of change in material consumption and cost of electricity used for production of products. The search for optimal values of the mentioned parameters is conducted. The structural model for carrying out imitative simulation of production process is proposed. The formal criterion for choosing one out of several plans on the basis of the proposed approach is formulated.
\end{abstract}

Keywords-management; process automation; structural model; innovative projects portfolio; resource economy

\section{INTRODUCTION}

Despite the steady trend in decrease of material resources contribution in the cost of most types of products, the question of resource saving remains important because of its great potential in cost reduction [1]. Implementation of new technologies and materials can change structure of pricing, but new approaches in manufacturing will require new assessments of the resulting resource cost and, therefore, the search for new ways of resource saving.

The opportunity of modernization of production on the basis of reduction in the volume of purchased materials and decrease in energy costs for the production process is considered in this paper.

Reduction in rates of materials consumption and energy costs within the implementation of innovative projects can be achieved due to the use of innovative materials and technologies. In recent years the market systematically offers new low-cost materials with incredible characteristics. New methods of data processing allow obtaining qualitatively new components. New opportunities help in finding original design solutions that serve the basis for improvement of design methods and development of innovative tools [2].

\section{MATHEMATICAL MOdEl of RESOURCE SAVING PRODUCTION}

The analysis of the plans of innovative projects introduction is to be carried out to find out the best plan that minimizes the objective function, the contribution of innovative technologies into each of production processes is to be examined for this purpose.

Thus the task is to select a set of innovative projects and the sequence of their implementation that allow minimizing intensity of production and production energy consumption within the time interval, where $\mathrm{T}$ is the planning horizon. Hereby the set of feasible versions of the plan of innovative projects implementation is to be formed.

The volume of production (output) will be assessed according to the production function: $Y(t)=F(K(t), L(t))$, which is considered to be linear and homogeneous [3]:

$$
\begin{aligned}
& F(\alpha * K(t), \alpha * L(t))=\alpha * F(K(t), L(t)) . \quad \alpha>0 \\
& Y(t)=a * K(t)+b * L(t)(2)
\end{aligned}
$$

Where ${ }^{L}$ - labor resources, $K$ - the main production assets, which depreciate with the rate $\mu>0$, and that means $K(t+\Delta t)=\mu * K(t) . \Delta t$ is discreteness of process modeling in the period of time.

Production function of the whole production can be divided into I production processes:

$$
\begin{aligned}
& Y_{i}(t)=a_{i} * K_{i}(t)+b_{i} * L_{i}(t) . \\
& Y(t)=\sum_{i=\mathbf{1}}^{I} Y_{i}(t)
\end{aligned}
$$


Part of the production processes will be changed during the realization of the $\mathrm{j}$-th version of the plan of innovative development. The plan includes one or more innovation projects and information about the sequence of their implementation:

$$
Y_{i j}(t)=a_{i j} * K_{i j}(t)+b_{i j} * L_{i j}(t) \text {. }
$$

If there are no changes in the $\mathrm{i}$-th production process within the implementation of the $\mathrm{j}$-th version of the plan

$$
a_{i j}=a_{i}, K_{i j}(t)=K_{i}(t), b_{i j}=b_{i}, L_{i j}(t)=L_{i}(t) \text {. }
$$

The share of profit, which is planned to be spent on the implementation of the $\mathrm{j}$-th plan of innovative development, we define as $s_{j}(t)$. Then, after the realization of the j-th plan of innovative development

$$
\begin{aligned}
& Y_{j}\left(t_{\text {mes }}+T\right)=\sum_{i=1}^{I} \sum_{n=0}^{W}\left(1-s_{j}(t)\right)\left(a_{i j}\right. \\
& \left.\mu_{j} \leqslant K_{i j}(t)+b_{i j} * L_{i j}(t)\right)_{y} \\
& \quad t=n * \Delta t \\
& T=N * \Delta t \geq T_{j}
\end{aligned}
$$

The sequence of realization of innovative projects in different versions of the plan of innovative development affects the volume of output, and therefore, on the share of the profits $s_{j}(t)$, which can be spent on the implementation of the $\mathrm{j}$-th innovation project.

Every production process converts the material resources $m_{i j}$ into the product $Y_{i j}(t)$ with energy consumption $e_{i j}$. We denote the current values of the indicated variables as $m_{\tilde{w}} Y\left(t_{\text {mex }}\right)_{y} e_{\mathrm{i}}$.

The resulting integral index $S_{j}$ of the material and energy consumption is estimated as a weighted linear combination of these indicators [4] for the time moment $\left(t_{\text {mes }}+T\right)$ of the realization of the $\mathrm{j}$-th innovation development plan:

$$
S_{j}=c \sum_{i=\mathbf{1}}^{I} m_{i j}+d \sum_{i=\mathbf{1}}^{I} e_{i j}(7)
$$

The values of the weight coefficients of the integral indicators are set in accordance with the decision maker (DM) preferences:

$$
\begin{aligned}
& c=c_{\text {MUP }} / \sum_{i=1}^{I} m_{i} \\
& d=d_{\text {MWP }} / \sum_{i=1}^{I} e_{i}
\end{aligned}
$$

We carry out the normalization to compare the results reduced to the same volume of production:

$$
\widehat{S_{j}}=S_{j} * Y\left(t_{\text {mex }}\right) / Y_{j}\left(t_{\text {mex }}+T\right)(8) \text {, }
$$

and choose the innovative development plan with a minimum value of $\widehat{S_{J}}$.

$\widehat{S_{J}}$ can be considered as the values of the objective function.

Thus, to select the innovative project it is necessary to form the set of all the variants of the plan for implementing innovative projects, including standards for production processes and the share of profit, which is to be spent on innovation. The objective function is to be formed on the basis of assessment of the need in material resources and estimation of the forecast of electricity consumption for each of the plan variants. To facilitate comparison all indicators are compared in accordance with current production volume.

\section{Structural Model of Simulative Modeling OF INNOVATIVE PROJECTS IMPLEMENTATION}

The formalized description of the process of an innovative project selection described in the paper is generic. The real decision-making procedure is to include more factors. Let's consider a comprehensive structural model of innovative development of production using the developed algorithm, which permits to take into account economic, social, and environmental consequences of each variant of innovative development plans for the enterprise. Similar models are widely used in practice of scientific research [5], [6], [7].

The input flow of material resources and the output flow of products are indicated by wide arrows in "Fig. 1". Thin arrows indicate the direction of transmission of the code sequences of the simulated data.

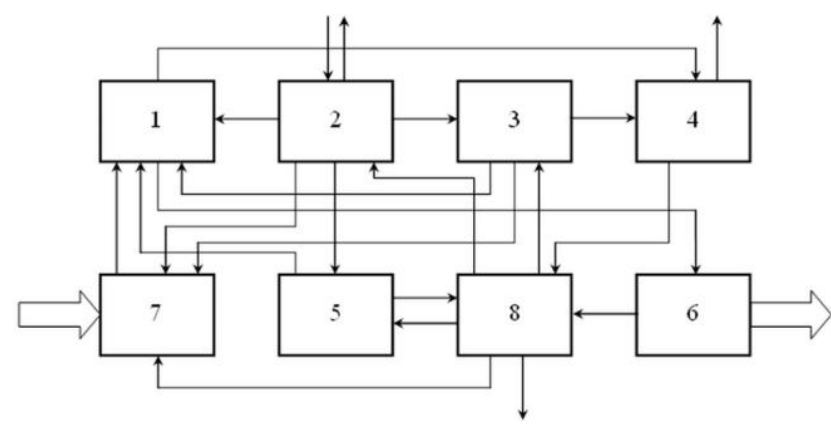

Fig. 1. Structural model of simulative modeling of innovative projects implementation.

The structural model includes the following units:

- Management of the production process and imitation of its implementation (Unit 1).

- Implementation of innovative projects and analysis of changes in product quality (Unit 2).

- Analysis of necessary measures to change the structure of production capacities (Unit 3). 
- Forecast for the environmental performance of the enterprise (Unit 4)

- Analysis of necessary measures in change of the number and retraining of staff (Unit 5).

- Sales of products (Unit 6).

- Ensuring supply with electricity and material resources (Unit 7).

- Assessment of profitability and ensuring financing for production (Unit 8).

The input data of the simulative model are:

- The data for each of the variant of the innovative activities plan such as the code sequence of the implemented technological processes and corresponding to them numerical data.

- Variants of options for share of profit, which is planned to be spent on innovation $s_{j}(t)$.

- The rate of depreciation of equipment $\boldsymbol{\mu}_{j} *$ standards for equipment utilization and proportional to them coefficients of the production function $a_{i j}$.

- Norms for consumption of materials and electricity $m_{i j p} e_{i j}$.

- Labor standards and proportional to them coefficients of the production function $b_{i j}$.

- The values of the coefficients $\mathrm{c}$ and $\mathrm{d}$ of the objective function.

- Current output $Y\left(t_{\text {mes }}\right)$.

The incoming data enter the Unit 2. At the output of the Unit 2 the value of the objective function of the model for realization of the current version of the innovative development plan is formed. The assessment of the impact of innovations on product quality parameters is also to be made at this stage. The financial results of the realization of the plan variant are the output data for the Unit 8. The changes in the company's ecological characteristics are analyzed at the output of the Unit 4 . The rest links form the restrictions for the set of possible solutions according to the possibilities of financing, production, and market circumstances. The simulative model of the production process is realized on the basis of code combinations that correspond to the planned parameters, the current innovation project, and the availability of necessary materials and equipment. Particular production conditions make it possible to assess the ecological parameters of the production in the Unit 4. The readiness of the staff of the enterprise to implement innovations (the Unit 5) directly depends on costs for retraining of personnel, changes in working conditions, and wages. These factors are determinants for the output volume (the Unit 6) and the resulting financial parameters (the Unit $8)$.

\section{CONCLUSION}

The criterion for the comparison of innovative projects based on resource saving is proposed. The scientific novelty of the article is in the development of the methodology of comparisons of cost of materials and energy consumption for various innovative projects after conversion them to the sole time interval and same volume of production. The comparison algorithm of innovative projects is based on the classical concepts of the production function, decomposition of production processes, and the formation of a convolution, id est measurable integral assessment of the comparison results. The simulation model which allows considering mutual influence of heterogeneous factors on the results of innovative projects implementation is developed.

The proposed approach to comparison of innovative projects allows formalizing the process of options assessment for innovative projects implementation and choosing the most appropriate variant for current conditions of successful enterprise functioning.

\section{REFERENCES}

[1] M.Ya.Veselovskiy, A.V. Nikonorova, Innovative Process Management and Trends of Innovations Implementation // Voprosy novoy ehkonomiki. 2014. № 2 (30). pp. 60-67.

[2] M.Ya. Parfenova, S.N. Malikov, Yu.V. Litvin, Formalization of modern mechanisms of management / Moscow, 2015

[3] R.Dzh. Barro, H. Sala-i-Martin, Economic growth // M.: Binom. 2010

[4] G.A. Royko, S.N. Malikov, S.M. Chudinov, The algorithm of determining the period of economic parameter changes / Obrazovatel'nye resursy i tekhnologii. 2013. № 2 (3). pp. 51-57.

[5] M.Ya. Parfenova, A.V. Semenov, The Model of production system management. Patent for utility model RUS 153307 26.06.2014

[6] V.A. Shumaev, S.N. Malikov, The model of a production system management on the basis of resources economy // Menedzhment i biznes-administrirovanie. 2016. № 4. pp. 51-58.

[7] V.A. Shumaev, A.A. Odintsov, A.A. Sazonov. V.V. Raniuk, N.I. Arkhipova and D.E. Morkovkin. Model of efficient cost reduction instrument for machine construction // Modern journal of language teaching metods. 2018. T.8. № 3. pp. 279-289. 